\title{
Patterns of Root and Alveolar-Bone Growth Associated with Development and Eruption of Teeth in Rhesus Monkeys
}

\author{
ERNEST B. KENNEY and SIGURD P. RAMFJORD \\ Department of Periodontics, School of Dentistry, University of Michigan, Ann Arbor, \\ Michigan 48104
}

Tritiated proline was used to follow the patterns of root growth and alveolar-bone production associated with tooth eruption in rhesus monkeys. Alveolar-bone deposition was seen around the apical regions of both erupting and functioning teeth, which indicated that the apical region was not spatially stable.

The main protein in alveolar bone and dentin is collagen. ${ }^{1}$ Two thirds of the total amino acids found in collagen are composed of glycine, alanine, proline, and hydroxyproline. ${ }^{1}$ The hydroxyproline in collagen is derived almost exclusively from hydroxylation of proline. Thus the proline molecule may enter collagen in two ways: as proline or as hydroxyproline. ${ }^{2-4}$

Many studies have used radioactive labels on proline to observe collagen metabolism. 3,5-10 Carneiro and Leblond ${ }^{7}$ found that collagenase removed almost all the tritiated proline labeling in dentin and bone, which supports the concept that proline in dentin and bone is largely attached to collagen. Leblond $s$ observed the incorporation of ${ }^{14} \mathrm{C}$ proline and ${ }^{3} \mathrm{H}$ glycine in developing dentin and noticed labeling of odontoblasts within five minutes of injection. Labeling appeared in the predentin in four hours and in the newly formed dentin in 35 hours. These results have been confirmed by several later studies which used tritiated proline ${ }^{5,7,9}$ and tritiated glycine. ${ }^{11}$

The initial labeling of developing dentin and bone by tritiated proline or glycine apparently is extremely stable. Anderson ${ }^{5}$ found an intense initial band of labeled proline in dentin and alveolar bone, which was

This investigation was supported by the Veterans Administration Hospital, Ann Arbor, Mich.

Received for publication July $8,1968$. still present 59 days after the injection of tritiated proline. However, there was evidence of decreasing amounts of labeling in the dentin and bone formed after the injection. In another study, ${ }^{3} \mathrm{H}$-proline labeling of alveolar bone was still present six months after injection. ${ }^{12}$

Although tritiated proline has been used to study collagen metabolism in bone and dentin, there has been little emphasis on the use of this label as a marker for bone and dentin production. Baumhammers et $\mathrm{al}^{12}$ compared growth increments of alveolar bone and frontal bone in mice using tritiated proline as a marker. Formicola and Ferringo, ${ }^{9}$ in a study using ${ }^{3} \mathrm{H}$ proline, mentioned alveolar-bone and cellular-cementum formation associated with eruption of teeth in the rat, but no quantitation of root or alveolar-bone growth was given.

The purpose of the present study was to use the fine labeling characteristics of tritiated proline as a marker of growth of bone and teeth in order to study the controversial relationship ${ }^{13-18}$ between the apex of the root and the surrounding bone in developing and erupting teeth.

\section{Materials and Methods}

Two male rhesus monkeys (Macaca mulatta) were used in this study. One monkey had the second permanent molars erupting; the other monkey had all teeth in function except four unerupted third molars.

The monkeys were injected intravenously with both tritiated thymidine $(1 \mathrm{mc} / \mathrm{gm}$ body weight, specific activity 6.7 curies/ millimol) and tritiated proline $(2 \mathrm{mc} / \mathrm{gm}$ body weight, specific activity $224 \mathrm{mc} / \mathrm{milli}$ $\mathrm{mol})$. The older animal was killed 30 days after the injection; the other, 90 days postinjection. At death, specimens of internal 
organs were taken for postmortem microscopic examination in order to insure that no systemic disease was present.

The jaws of the animals were fixed in $10 \%$ neutral formalin for three weeks. The maxilla and mandible were cut buccolingually into sections containing one or two teeth and were decalcified in $20 \%$ ethylenediamine tetracetic acid at $\mathrm{pH}$ 7.4. The tissue specimens were then washed in running water overnight, embedded in paraffin, and sectioned buccolingually at $8 \mu$.

Radioautography was carried out on a number of sections from each tooth, using the technic described earlier. ${ }^{19}$ After four weeks' exposure, the radioautographs were developed and fixed, the slides were stained with Ehrlich's acid hematoxylin, and were mounted with permount. Approximately every fifth section was counterstained with eosin.

In this paper, only the labeling associated with the tritiated proline will be reported.

For each tooth, one section which was closest to the long axis of the tooth was selected. Two serial sections on either side of the central section were also measured, to insure that the labeling was typical of the central part of that tooth.

The tritiated proline clearly labeled growing bone, dentin, and cementum, and on each section the following measurements were made (Fig 1):

1. INCREASE IN ROOT LENGTH.-The distance from the apex of the tooth to the most apical part of the proline label of the root.

2. INCREASE IN FUNDIC BONE.-The vertical distance from the border of the alveolar bone immediately below the central axis of the tooth to the previously corresponding area outlined by the tritiated proline.

3. Tooth APEX TO FUNDIC BONE.-The distance between the apex of the tooth and the fundic bone below the central axis of the tooth.

The sections of teeth were divided into three groups:

1. Erupted and functional teeth.

2. Unerupted teeth still enclosed in bony crypt.

3. Teeth erupted into the mouth but not yet in function.

A micrometer disk with a $10-\mathrm{mm}$ scale in a $\times 10$-wide angle eyepiece was used to measure increments of bone growth and in-

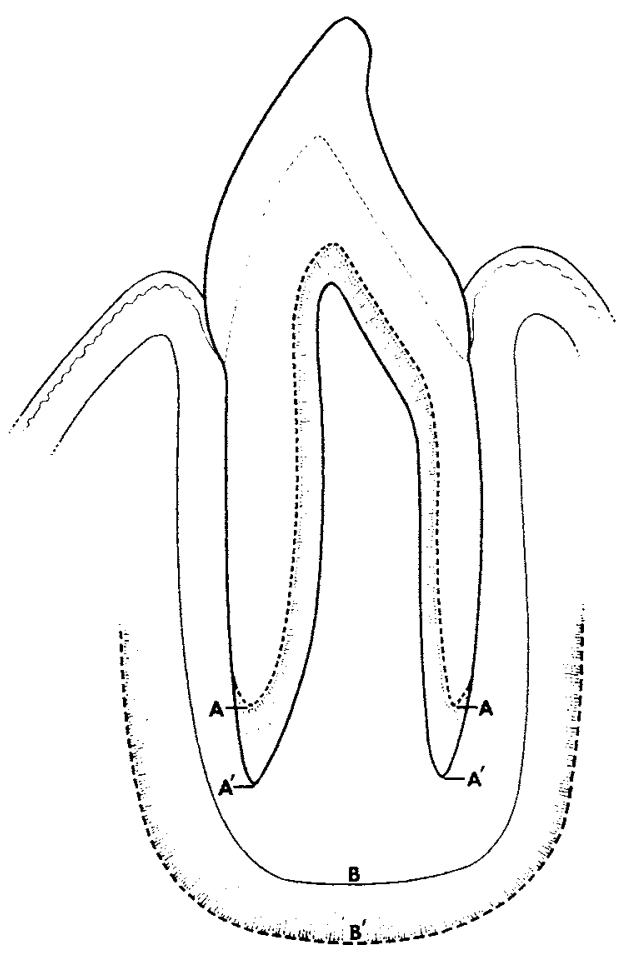

FIG 1.--Diagram of section of teeth studied. Dotted line, ${ }^{3} \mathrm{H}$-proline labeling. Increase in root length measured from $A$ to $A^{\prime}$. Increase in fundic bone measured from $B$ to $B^{\prime}$. Width of periodontal space at apex measured from $A^{\prime}$ to $B$.

crease in root length. A $\times 10$ objective lens was used for the 30-day sections, and a $\times 4$ objective lens was used for the 90-day section. A mechanical stage was used, and the direct measurements from the microscope were converted to millimeters.

Results were tabulated, and comparisons were made of root growth and bone deposition in the apical region at the various stages of development.

\section{Results}

Tritiated proline became incorporated in tissues which were calcifying at the time of injection. This initial accumulation of proline in bone, dentin, and cementum was seen on the autoradiographs as a thin band of dense labeling. Proline continued to label calcifying tissues for some time after the injection. This subsequent labeling extended from the initial dense band of labeling to the periphery of the newly calcified tissues 
as a fine widely dispersed label (Fig 2). At 90 days after injection, bone, dentin, and cementum still had some dispersed labeling in the regions of newly formed tissues.

The connective tissues throughout the sections also were labeled with tritiated proline. This labeling was less concentrated than that seen in calcified tissues and could hardly be differentiated from "background."

In bone, the pattern of use and accumulation of labeled proline made it possible to determine in which direction new bone deposition had occurred. The bone surrounding the root apex of erupting and functioning teeth showed labeling with proline in all instance in the 90-day animal (Fig 3). The pattern of labeling indicated new bone growth in this region. The amount of new apical bone formation, measured using the micrometer eyepiece disk, is given in the table.

Teeth which were erupting into the oral cavity showed the most increase in apical bone formation, although fundic bone was laid down apically to some teeth which were functioning. Apical bone formation was seen in one tooth which was enclosed in a bony crypt and was at an early stage of root development; but three other teeth in the early stages of development showed no such bone formation.

Increase in root length was seen in all the teeth studied. This increase was due to formation of both cementum and dentin. In teeth which were still at the stage of root formation, the growth of dentin was much greater than the growth of cementum (Fig 4). Teeth which had been in function for some time and had completed most of their

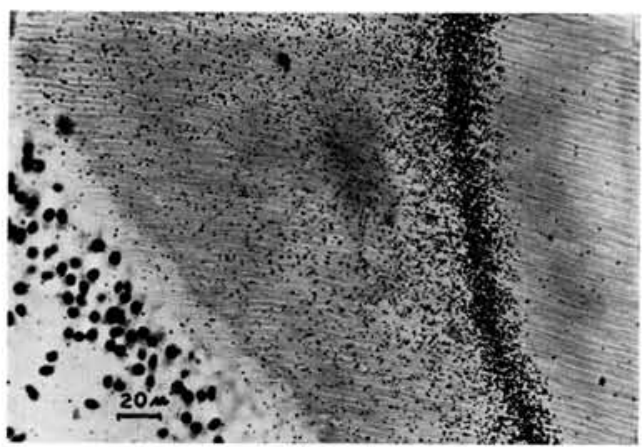

FIg 2.- ${ }^{3} \mathrm{H}$-proline labeling of dentin 90 days after injection, showing dense initial label and dispersed subsequent label (orig mag $\times 430$ ).

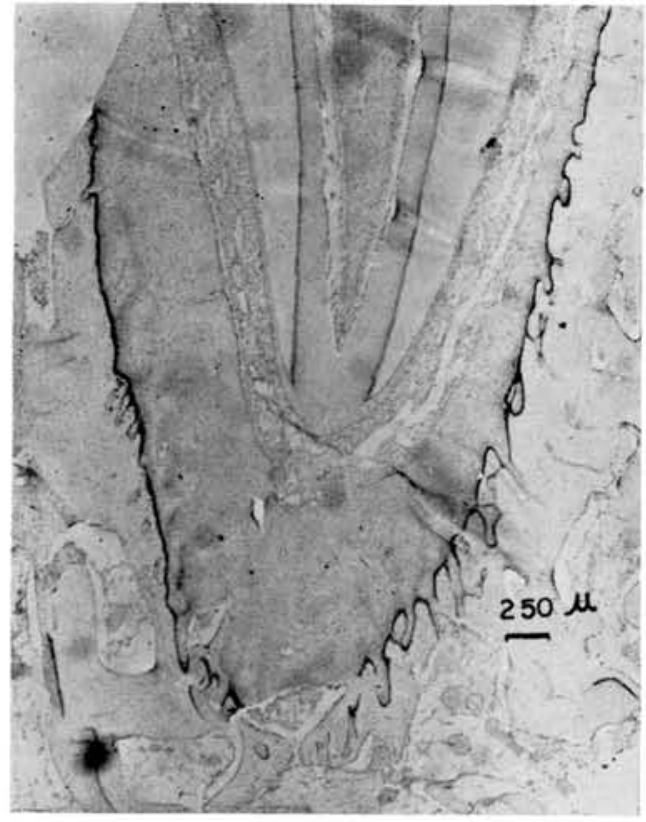

FIG 3.- ${ }^{3} \mathrm{H}$-proline labeling of alveolar bone 90 days after injection (orig mag $\times 23$ ).

root formation showed smaller increments of root growth; most of this increase was in cementum.

The pattern of labeling of developing roots was always the same: the tritiated proline was laid down in cementum and dentin as a V-shaped band corresponding to the pattern of calcification of the root (Fig 5).

Labeling of cementum was rarely seen in the more coronal regions of the root. The proline accumulated mainly in the apical third of the teeth, which indicated that new cementum formation was largely confined to the region of the root apex.

Dentin formation in developing roots was seen all around the periphery of the future dental pulp, although the largest growth increments occurred at the developing root apex. There was no labeling associated with the preodontoblastic root extension described in a previous paper, ${ }^{20}$ thus confirming that this amorphous structure does not calcify.

\section{Discussion}

There was no evidence of bone deposition associated with the apical regions of the two teeth with developing roots, which suggests that no occlusal movement with dep- 
Increments of Root Growth, Apical Alveolar Bone Production, and Width of Periodontal Space at Tooth Apex

\begin{tabular}{|c|c|c|c|c|c|}
\hline & & & $\begin{array}{c}\mathrm{A}-\mathrm{A}^{\prime} \\
\text { Increase in } \\
\text { Length } \\
\text { of Tooth } \\
(\mathrm{mm})\end{array}$ & $\begin{array}{c}\text { B-B' } \\
\text { Increase in } \\
\text { Apical } \\
\text { Alyeolar } \\
\text { Bone } \\
\text { (mm) } \\
\end{array}$ & $\begin{array}{c}\text { A'-B } \\
\text { Distance } \\
\text { from Root } \\
\text { Apex to } \\
\text { Alveolar } \\
\text { Bone } \\
(\mathrm{mm})\end{array}$ \\
\hline Preroot formation & $\begin{array}{r}\# 17 \\
\# 1\end{array}$ & $\begin{array}{l}90 \text { days } \\
90 \text { days }\end{array}$ & $\begin{array}{l}0.78 \\
0.73\end{array}$ & $\begin{array}{l}\text { None } \\
\text { None }\end{array}$ & $\begin{array}{l}0.38 \\
0.78\end{array}$ \\
\hline Early root formation & $\begin{array}{l}\# 16 \\
\# 32\end{array}$ & $\begin{array}{l}30 \text { days } \\
30 \text { days }\end{array}$ & $\begin{array}{l}0.18 \\
0.26\end{array}$ & $\begin{array}{l}0.03 \\
\text { None }\end{array}$ & $\begin{array}{l}0.22 \\
1.01\end{array}$ \\
\hline Erupting into mouth & $\begin{array}{l}\# 15 \\
\# 29 \\
\# 28 \\
\# 20 \\
\# 2\end{array}$ & $\begin{array}{l}90 \text { days } \\
90 \text { days } \\
90 \text { days } \\
90 \text { days } \\
90 \text { days }\end{array}$ & $\begin{array}{l}1.30 \\
1.13 \\
1.65 \\
1.28 \\
1.68\end{array}$ & $\begin{array}{l}0.58 \\
2.37 \\
1.60 \\
1.75 \\
1.28\end{array}$ & $\begin{array}{l}0.68 \\
0.56 \\
0.65 \\
0.73 \\
0.73\end{array}$ \\
\hline Erupted & $\begin{array}{r}\# 6 \\
\# 8 \\
\# 30 \\
\# 15 \\
\# 18 \\
\# 17 \\
\# 28\end{array}$ & $\begin{array}{l}30 \text { days } \\
30 \text { days } \\
30 \text { days } \\
30 \text { days } \\
30 \text { days } \\
30 \text { days } \\
30 \text { days }\end{array}$ & $\begin{array}{l}0.13 \\
0.04 \\
0.02 \\
0.20 \\
0.23 \\
0.22 \\
0.10\end{array}$ & $\begin{array}{c}0.17 \\
0.08 \\
0.08 \\
\text { None } \\
\text { None } \\
\text { None } \\
\text { None }\end{array}$ & $\begin{array}{l}0.47 \\
0.43 \\
0.15 \\
0.44 \\
0.10 \\
0.30 \\
0.45\end{array}$ \\
\hline & $\begin{array}{l}\# 3 \\
\# 6\end{array}$ & $\begin{array}{l}90 \text { days } \\
90 \text { days }\end{array}$ & $\begin{array}{l}0.13 \\
0.18\end{array}$ & $\begin{array}{l}1.63 \\
1.68\end{array}$ & $\begin{array}{l}0.65 \\
0.15\end{array}$ \\
\hline
\end{tabular}

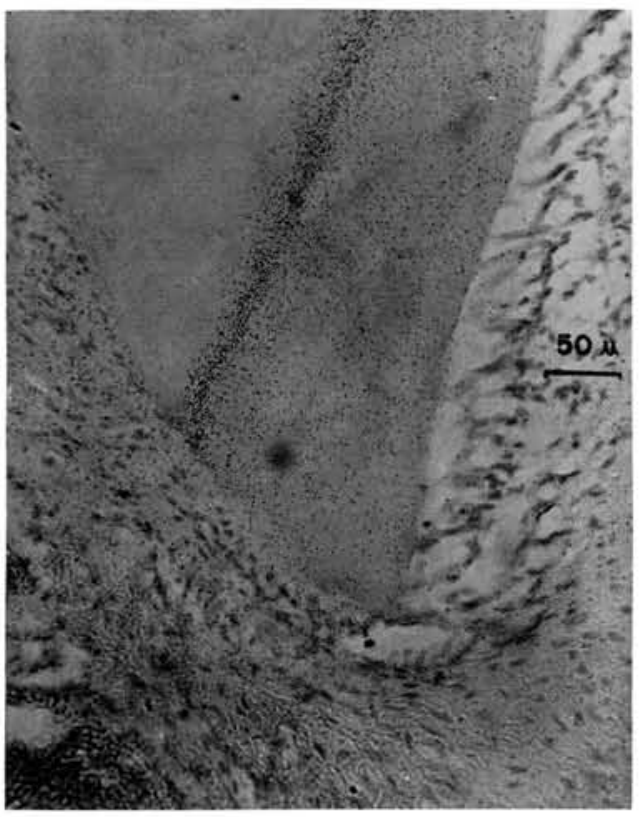

FIG 4.- ${ }^{3} \mathrm{H}$-proline labeling of developing root apex at 30 days, showing increase of root length due to dentin production (orig $\operatorname{mag} \times 236)$.

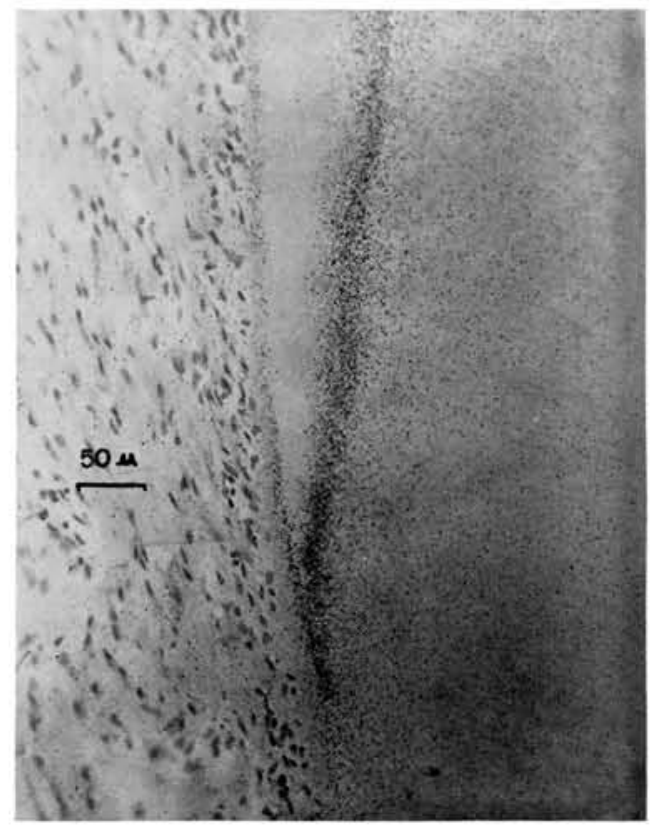

FIG 5. $-{ }^{3} \mathrm{H}$-proline labeling of dentin and cementum in V-shaped pattern (90 days) (orig mag $\times 208)$. 
osition of bone at the fundus had occurred. Baume, ${ }^{21}$ in a histologic and radiographic study of eruption in the rhesus monkey, made similar observations; Carlson, ${ }^{22}$ in a cephalometric study of developing teeth in children, reported that there was either a decrease or no change in the distance between the lower border of the mandible and the open ends of the developing crowns.

Most authors ${ }^{15,23-26}$ have reported a pattern of apical bone deposition after root formation has begun, but Baume ${ }^{21}$ saw bone resorption, and, then, later in root development, bone deposition. In the present study, apical bone deposition occurred around all the erupting teeth and many of the functioning teeth during the 90-day period of investigation. It therefore seems unlikely that the apical region is a stable point from which eruption occurs, as has been suggested previously. ${ }^{13,18,27}$ However, it must be remembered that eruption of a tooth into the oral cavity will be accompanied by remodeling of the alveolar process of the maxilla or mandible. Therefore, even though a tooth may be moving with respect to the immediate bone around it, the resultant eruptive movement into the mouth will be modified by resorption or deposition of the alveolar process and by any increase in root length.

Although this study was concerned only with measurement of the vertical movements of alveolar-bone growth, there was in all cases evidence of lateral movement of the socket during eruption of the tooth.

Increase in root length was present to some degree in all the teeth studied. If it is assumed that the distance between the developing root apex and the apical alveolar bone is constant, then the amount of vertical tooth movement would be equal to the increase of root length plus the movement of vertical alveolar-bone growth of the apex. Thus, at 90 days, the maximum amount of vertical tooth movement seen was $3.50 \mathrm{~mm}$.

Teeth which were in functional position before injection of the tritiated proline also showed increase in root length, and some showed bone deposition. This active eruption is thought to be a compensation for attrition. ${ }^{15,24,25,28}$

Some investigators ${ }^{14,25,29}$ believe that growth of bone lining the socket is an important mechanism causing eruption, whereas others ${ }^{16,26}$ feel that this bone is passively laid down as a result of tooth movement. In this investigation, it was not possible to relate these changes directly to the mechanism of eruption.

\section{Conclusions}

The production of alveolar bone around the apexes of erupting and functioning teeth indicated that the apical region is not spatially stable but is an area of dynamic bone deposition.

Further studies are required to investigate the changes occurring in the entire bony crypt around erupting teeth.

The deposition of bone was associated with an increase in root length. The root growth in erupting teeth consisted mainly of dentin with a much smaller increment of cementum, whereas functioning teeth showed much less root growth, which was mainly an increase in cementum.

It is likely that the increase in root length and the deposition of fundic bone in teeth which were functioning for some time may be a compensatory mechanism associated with attrition. This requires further investigation.

The administration of the isotopes was by Carlos $E$. Nasjleti, and the histologic sections and radioautographs were prepared by Jean I. Simons and Virginia $W$. Hartog at the Veterans Administration Hospital, Ann Arbor, Mich.

\section{References}

1. Eastoe, J.E.: The Amino Acid Composition of Proteins from the Oral Tissue. II. The Matrix Proteins in Dentin and Enamel from Developing Human Teeth, Arch Oral Biol 8:633-652, 1963.

2. DeIss, W.P.; Holmes, L.B.; and Johnston, C.L.: Bone Matrix Biosynthesis In Vitro, Labeling of Hexosamine and Collagen of Normal Bone, J Biol Chem 237:3555-3559, 1962.

3. Hausmann, E., and Newman, W.F.: Conversion of Proline to Hydroxyproline and Its Corporation into Collagen, J Biol Chem 236:149-152, 1961.

4. Mitoma, C.; Smith, T.E.; Friedberg, F.; and RAYFORD, C.: Incorporation of $\mathrm{Hy}$ droxyproline into Tissue Proteins by Chick Embryos, J Biol Chem 234:78-80, 1959.

5. Anderson, A.: The Protein Matrixes of the Teeth and Periodontium in Hamsters, $J$ Dent Res 46:67-78, 1967.

6. Tonna, E.A.: A Study of Osteocyte Formation and Distribution of Aging Mice 
Complemented with $\mathbf{H}_{3}$ Proline Autoradiography, J Geront 21:124-130, 1966.

7. Carneiro, J., and Leblond, C.P.: Suitability of Collagenase Treatment for the Autoradiographic Identification of Newly Synthesized Collagen Labeled with $\mathrm{H}_{3}$ Glycine or $\mathrm{H}_{3}$ Proline, $J$ Histochem Cytochem 14:334-344, 1966.

8. LEBLOND, L.P.: Elaboration of Dentinal Collagen in Odontoblasts as Shown by Radiography after Injection of Labeled Glycine and Proline, Ann Histochim 8:43-50, 1963.

9. Formicola, A.J., and Ferringo, P.D.: A Radiographic Study of the Developing Periodontium of the Rat, Periodontics 4: 297-301, 1966.

10. Ross, R., and BENDITT, E.P.: Wound Healing and Collagen Formation, $J$ Cell Biol 27:83-106, 1965.

11. Young, R.W., and Greulich, R.L.: Distinctive Autoradiographic Patterns of Glycine Incorporation in Rat Enamel and Dentin Matrices, Arch Oral Biol 8:509-521, 1963.

12. Baumhammers, A.; Stallard, R.E.; and ZANDER, H.A.: Remodeling of Alveolar Bone, J Periodont 36:439-442, 1965.

13. Diab, M.A., and Stallard, R.E.: A Study of the Relationship between Epithelial Root Sheath and Root Development, Periodontics 3:10-14, 1965 .

14. Brash, J.C.: The Growth of the Alveolar Bone and Its Relation to the Movements of the Teeth, Including Eruption. Int $J$ Ortho Oral Surg and Radiog 14:196-223; 283-293; 398-405, 1928.

15. Weinmann, J.P.: Bone Changes Related to Eruption of the Teeth, Angle Orthodont 1:83-99, 1941

16. Hoffman, M.M., and Schour, I.: Quantitative Studies in the Development of the Rat Molar, Amer $J$ Orth and Oral Surg 26:854-874, 1940.

17. OrBan, B.: Growth and Movement of the Tooth Germs and Teeth, JADA 15:1004$1016,1928$.
18. Orban, B.: Epithelial Rests in the Teeth and Their Supporting Structures, Proc 5th Annual Meeting of the Amer Assoc of Dental Schools, 1928, p 121-133.

19. ENGLER, W.O., RaMFJORD, S.P., and HiniKER, J.J.: Development of Epithelial Attachment and Gingival Sulcus in Rhesus Monkeys, J Periodont 36:44-57, 1965.

20. KenNey, E.B., and RAMFJord, S.P.: Cellular Dynamics in Root Formation of Teeth in Rhesus Monkeys, $J$ Dent Res, in press.

21. Baume, L.J.: The Development of the Lower Permanent Incisors and Their Supporting Bone, Amer J Orthodont 39:526544, 1953.

22. Carlson, H.: Studies on the Rate and Amount of Eruption of Certain Human Teeth, Amer J Orth and Oral Surg 30: 575-588, 1944.

23. KRonfeld, R.: The Resorption of the Roots of the Deciduous Teeth, Dent Cosmos 74:103-20, 1932.

24. Schour, I. (ed) in Noyes' Oral Histology and Embryology, 8th ed, Philadelphia: Lea \& Febiger, 1960, 440 pp.

25. Orban, B.: Oral Histology and Embry. ology, 3d ed, St. Louis: C. V. Mosby Co., 1953, 363 pp.

26. Thomas, H.E.: The Role of Collagen Maturation in Alveolar Bone Growth and Tooth Eruption, $J$ Dent Res 43(abstr): 947, 1964.

27. MCHUGH, W.D., and ZANDER, H.A.: Cell Division in the Periodontium of Developing and Erupted Teeth, Dent Pract (Bristol) 15:451-457, 1965.

28. Gottlieb, B., and Orban, B.: Biology and Pathology of the Tooth and Its Supporting Mechanism, Trans and ed Diamond, M., New York: Macmillan Co., 1938, p 64.

29. BoDECKER, C.F.: Concerning Organs Affecting the Eruption of Human Teeth, Int $J$ Orth Oral Surg and Radiog 14:657-667, 1928. 